\title{
geografia
}

Malaysian Journal of Society and Space

\section{Pola sokongan pengundi muda sebelum Pilihan Raya Umum ke 14 di Malaysia}

\author{
Yazid Saleh, Siti Noranizahhafizah Boyman, Hanifah Mahat, Mohmadisa Hashim, Nasir Nayan \\ Saiyidatina Balkhis Norkhaidi, Samsudin Suhaili \\ Jabatan Geografi \& Alam sekitar, Fakulti Sains Kemanusiaan, \\ Universiti Pendidikan Sultan Idris \\ Correspondence: Yazid Saleh (yazid@fsk.upsi.edu.my)
}

Received: 19 November 2019; Accepted: 20 February 2020; Published: 27 February 2020

\begin{abstract}
Abstrak
Artikel ini bertujuan untuk menganalisis pola pengundian dalam kalangan orang muda di Malaysia pada Pilihan raya Umum ke 14. Sebanyak lima domain utama iaitu pihak yang disokong, kriteria pemilihan, ciri-ciri calon, dasar parti dan isu semasa telah dipilih untuk melihat pola pemilihan ini. Kajian ini menggunapakai data primer yang diperoleh dari 47,116 responden daripada 98 Parlimen yang dipilih secara rawak sistematik serta data sekunder yang diperolehi dari buku, jurnal serta keratan akhbar. Analisis data primer melibatkan analisis frekuensi, peratusan, min dan sisihan piawai untuk meneliti profil responden dan tahap. Manakala analisis cross tab digunakan untuk melihat hubungan antara beberapa pemboleh ubah kajian, manakala data sekunder pula dianalisis menggunakan kaedah analisis dokumen. Berdasarkan analisis diadapati bahawa wujud kecederungan orang muda terhadap domain-domain tertentu berdasarkan latarbelakang pendidikan, umur, jantina serta lokasi kawasan. Kesimpulannya, penemuan kajian ini menunjukkan bahawa golongan muda memiliki perspektif yang tersendiri dalam pemilihan calon pilihanraya. Bagi mendapatkan sokongan dari orang muda, kriteria-kriteria yang telah dibincangkan tadi mestilah seiring dengan jiwa orang muda.
\end{abstract}

Kata kunci: kecenderungan, orang muda, PRU 14, pengundi muda, pilihan raya umum, pola pengundian

\section{Malaysian's young voter selection pattern before Malaysian 14 General Election}

\begin{abstract}
This article aims to analyze the pattern of voting among young people of Malaysia in the 14th General Election. A total of five domains, including supported parties, selection criteria, candidate characteristics, party policies and current issues, were utilised to analyse the voting pattern of the election. This research uses primary data obtained from 47,116 respondents of
\end{abstract}


98 parliamentary seat which were randomly selected using the systematic random selection and secondary data obtained from books, journals and newspaper clippings. All primary data were analyzed using 'cross tab' and 'regression' analysis methods, while secondary data was analyzed using 'trigulation' method and document analysis. Based on the analysis it was found that the existence of young people's trends towards certain domains based on educational background, age, gender and location of the area. In conclusion, this finding suggests that young people have their own perspective in the election of electoral candidates. To get support of the young voters, the criterias that have been discussed should be in line with the young voter's aspiration.

Keywords: tendency, young people, GE 14, young voter, General Election, pattern of voting

\section{Pengenalan}

Generasi muda adalah generasi pewaris kepimpinan negara pada masa hadapan. Mereka merupakan aset terpenting kepada negara dalam menjana pembangunan. Dari segi politik, orang muda merupakan satu entiti yang sering cuba disantuni sama ada kerajaan mahupun pembangkang bagi memenangi pilihanraya. Penglibatan orang muda dalam pembentukan landskap politik tempatan tidak dapat dinafikan. Ia bukan sahaja berlaku dalam negara ini, tetapi merebak ke seluruh dunia. Dalam konteks Malaysia, setelah berlangsungnya 14 Pilihan Raya Umum (PRU), didapati PRU12, PRU13 dan PRU 14, orang muda (baca-Pengundi Muda) telah menjadi salah satu elemen penyumbang peratus atau penentu kemenangan sesuatu parti politik. Dalam perbincangan ini orang muda dirujuk kepada meraka yang mendaftar sebagai pengundi dan berumur di antara 21-40 tahun.

Menerusi peningkatan arus kemodenan yang dirasai di seluruh negara, ia secara langsung memberikan impak besar kepada meningkatnya tahap literasi politik atau celik politik dalam kalangan masyarakat khususnya orsng muda. Berbanding dengan golongan yang lebih berumur yang seringkali dilihat mengamalkan 'politik lama' seperti tidak berani berubah dan mengenang jasa, golongan muda/belia pula dilihat sebaliknya. Mereka dilihat lebih bersifat 'anti establishment' dan dalam konteks negara ini, kumpulan tersebut adalah pembangkang. Dalam konteks dinamika politik hari ini mereka dilihat yakin bahawa undian mereka terhadap sesuatu parti politik akan memenuhi harapan dan dapat menyediakan masa depan yang cerah untuk mereka.

Kesedaran meluas terhadap politik juga mampu menjadikan seseorang pengundi muda lebih kritikal. Bagi pengundi muda, pemilihan seseorang calon wakil rakyat bukan hanya bergantung kepada faktor personaliti semata-mata, tetapi lebih melebar kepada soal latar belakang calon dan juga parti yang mereka wakili. Selain itu, trend pengundian orng muda juga banyak dipengaruhi soal yang berkait rapat dengan kepentingan mereka. Antaranya seperti soal kenaikan kos yang membebankan kehidupan harian, peluang pekerjaan, rumah mampu milik serta peluang pekerjaan yang kian terhad ditawarkan yang pada pandangan mereka memerlukan penyelesaian segera. Pengundi muda kini lebih matang dan lantang bersuara mengenai isu yang dihadapi mereka selain sukar untuk terpengaruh dengan sentimen politik perkauman.

Dalam siri PRU yang terdahulu, pengundi muda sering diabaikan dalam pilihanraya. Mereka dianggap sebagai golongan yang tidak cakna dalam keadaan politik semasa negara. Namun keadaannya kini sudah mula berubah. Semenjak PRU 12, pengundi muda mula dirasai peranannya dalam konteks politik Malaysia apatah lagi pada era kemerosotan pengaruh Barisan Nasional (BN) di Malaysia. Contoh yang paling ketara ialah strategi yang 
digubal oleh parti-parti politik dalam menawan hati pengundi muda di terjemahkan dalam manifesto masing-masing.

Dalam manisfesto Barisan Nasional (BN) dan Pakatan Harapan (PH), kedua-dua parti ini meletakkan agenda peluang pekerjaan, pendidikan, rumah mampu milik serta akses kepada kemudahan sukan dan rekreasi bagi memenuhi aspirasi dan harapan orang muda di Malaysia. Pengenalan ini jelas membuktikan bahawa betapa besar pengaruh pengundi muda dalam PRU di Malaysia. Oleh yang demikian, kajian ini bertujuan untuk melihat pola pemilihan pengundi muda dalam PRU ke 14 yang lalu. Perbincangan akan merujuk siapa yang disokong, apa kriteria pemilihan, apa aspirasi yang dibawa oleh parti yang disokong dan lain-lain.

\section{Pengundi muda dan kecenderungan memilih dalam pilihan raya}

Secara umumnya, orang muda mempunyai sisi pandangan yang sangat berbeza dari segi politik, mereka tidak tertarik dengan politk perkauman serta politik lama yang bersifat 'terhutang budi'. Dalam konteks Malaysia, beberapa kajian dan penelitian telah berjaya membincangkan tentang orang muda dan kecenderungan mereka untuk memilih calon dalam sesebuah pilihan raya.

Dari segi kesedaran pula, Abdul Hadi (2014) pula berpendapat penglibatan belia dalam PRU yang lepas amat meruncing. Buktinya, 60 peratus dari keseluruhan 3.7 juta belia tidak mendaftar sebagai pengundi dan antara alasan yang sering diberi ialah mereka sibuk dengan pengajian dan sibuk dengan pekerjaan. Selain itu, penglibatan belia dalam persatuan badan bukan kerajaan (NGO) juga rendah. Secara keseluruhan tahap penglibatan politik belia adalah rendah, walau bagaimanapun pengaruh media massa dan persekitaran sosial mampu mempengaruhi pengibatan politik belia.

Selain itu, kajian Weiss (2011) juga menunjukkan aktivisme pelajar di Malaysia telah mengalami perkembangan dan kemerosotan. Hal ini kerana, pelajar universiti pada zaman kontemporari adalah bersifat pasif dalam kegiatan aktivisme. Perkara ini diakibatkan oleh pendekatan pedagogi dan institusi akademik yang sedia ada telah menyekat pelajar dan tenaga mengajar untuk melibatkan diri dalam kegiatan aktivisme. Perkara ini sudah tentu akan memberi implikasi kepada politik perdana. Selari dengan kajian Siti Noranizahhafizah (2017) mendapati tahap pengetahuan mahasiswa mengenai perkembangan pilihan raya kampus adalah rendah. Namun, tahap pengetahuan mahasiswa tentang proses pilihan raya adalah tinggi. Selain itu, laman web merupakan sumber utama pengaksesan maklumat politik dalam kalangan mahasiswa. Dapatan juga menunjukkan mahasiswa perempuan UPSI menunjukkan tahap penglibatan politik kampus yang lebih tinggi. Selain itu, calon, manifesto dan isu semasa merupakan faktor utama yang mempengaruhi pilihan mahasiswa.

Namun, Welsh \& Hsien Chang (2012) mengatakan keadaan politik di Malaysia telah matang untuk pemuda memainkan peranan yang lebih penting dalam membawa perubahan demokrasi, sebahagian besarnya disebabkan oleh bidang politik yang berpotensi berbanding dengan sikap mereka yang mendasari. Dalam kajiannya, menunjukkan bahawa tidak boleh menolak pemuda sebagai kuasa besar dalam membawa perubahan dalam pilihan raya akan datang.

Walaupun dikatakan kurang kesedaran tetapi peranan dan pilihan orang muda sangat penting dalam sesebuah pilihanraya. Sebagai contoh, kajian Mujibu et al. (2011), mempamerkan kemunculan generasi baharu dalam pilihan raya jelas menunjukkan bahawa generasi di Malaysia telah beranjak dari generasi merdeka kepada pasca merdeka. Perubahan ini menjadikan politik pilihan raya di Malaysia menarik untuk dikaji. Ini kerana perubahan generasi menuntut kepada perubahan strategi untuk memancing undi. Dalam hal ini BN 
dikatakan gagal untuk beradaptasi dengan perubahan tersebut. $\mathrm{BN}$ yang berterusan menggunakan politik pembangunan gagal tampil dengan strategi baru untuk memikat pengundi muda. Tambahan pula, beberapa isu, kontroversi dan kelemahan pentadbiran kerajaan diteraju $\mathrm{BN}$ memburukkan lagi reputasi $\mathrm{BN}$ di mata rakyat, terutamanya golongan muda/belia. Justeru itu, artikel ini turut meneliti perubahan perkembangan dan amalan demokrasi di dalam masyarakat Malaysia yang majmuk sifatnya.

Manakala Müller (2013) dalam kajiannya mendapati elit Pemuda PAS secara konsensual menegakkan matlamat Islamisme politik berorientasi negara dan bahkan melakukannya dengan semangat baru dan bertentangan dengan kecenderungan terhadap pragmatisme politik yang muncul di kalangan bahagian kanan parti. Oleh itu, ia membawa makna bahawa pengundi muda mempunyai prinsip dalam mengangkat idea politik mereka tanpa dipengaruhi oleh kekananan

Selepas PRU-12, jelas BN tidak boleh mengelak dari memenuhi tuntutan politik baharu yang lebih terbuka dan sejagat. Namun begitu, tuntutan politik baru ini masih lagi tidak matang dan boleh diterima sebagai benar-benar sejagat. Jika diteliti, ianya masih lagi membawa unsur-unsur lama yang dikonstruksikan mengikut kaca mata perkauman. Sebenarnya generasi telah berubah, kemajuan ICT dan globalisasi sedikit sebanyak menghakis perkauman dalam sistem politik Malaysia. Namun, masih tiada tanda-tanya yang boleh menjamin bahawa perkauman itu akan lenyap terus dari lanskap politik Malaysia.

Dari segi pola pengundian pula, Mohd Haziman (2017) mendapati sejak pilihan raya umum 2008 (PRU 12), pola pengundian telah memperlihatkan perubahan yang signifikan pengundi muda kepada pembangkang. Perubahan ini adalah disebabkan oleh rasa tidak puas hati pengundi muda terhadap $\mathrm{BN}$ sehingga terhakisnya hegemoni $\mathrm{BN}$ dan akhirnya mencetuskan tsunami politik. Trend yang sama turut berlaku dalam PRU 13 (2013) apabila BN sekali lagi memenangi pilihan raya dengan majoriti yang berkurangan, iaitu memenangi sebanyak 133 kerusi sahaja daripada 222 kerusi yang dipertandingkan. Kemerosotan pencapaian BN dalam PRU 13 adalah disebabkan oleh beberapa isu lama dan baharu dan juga kerana perubahan tingkah laku pengundi muda yang telah bersedia untuk memberi peluang kepada parti pembangkang. Beliau menambah bahawa penyertaan pengundi muda telah menghakis hegemoni $\mathrm{BN}$, memberi kesan kepada politik federalisme, dan juga membawa Malaysia ke arah pembentukan sistem dua parti. Walaupun penyertaan anak muda ini telah membawa kesan kepada pendemokrasian politik Malaysia, namun penyertaan mereka belum berjaya menggantikan kerajaan pemerintah, tetapi sekadar mampu menggugat hegemoni kuasa BN sahaja.

Namun begitu Mohd Nizar et al. (2017) menegaskan bahawa dengan mengatakan yang undi orang muda sahaja mampu menentukan keputusan pilihan raya umum mungkin sesuatu yang berlebihan, tetapi BN berpotensi kehilangan kuasa buat kali pertama sekiranya majoriti besar pengundi muda mengundi pembangkang. Justeru itu, pengundi muda menjadi semakin penting dan mampu untuk menjadi faktor penentu keputusan pilihan raya. Melalui langkah penyenaraian lebih ramai generasi muda sebagai calon PRU-14, ia suatu langkah penting dalam melahirkan lebih ramai pemimpin pelapis dalam BN terutama UMNO. Sekiranya sesebuah parti ingin mendapat kepercayaan rakyat, calon muda dan pemimpinpemimpinnya perlu mendekati rakyat dan memperjuangkan masalah-masalah yang dihadapi mereka. Keterlibatan calon muda dan pemimpin parti perlulah disertai oleh semua ahlinya bukan segelintir ahli sahaja. Dengan landskap politik kini sudah berbeza, ini sekali gus memerlukan parti melakukan perubahan untuk memastikannya terus kekal relevan.

Manakala dari aspek kecenderungan orang muda pula, Junaidi dan Mohd Fuad (2012), dalam kajian tentang keperluan belia dan pendapat politik di kawasan Parlimen Muar, Johor didapati bahawa kecenderungan belia memilih dari aspek ekonomi, kerana inginkan peluang pekerjaan yang bersesuaian dengan kelayakan mereka di samping tingkat upah/gaji 
yang sesuai dengan keadaan ekonomi semasa. Bagi aspek sosial pula, mereka menuntut supaya kemudahan jalur lebar/internet diperluaskan di samping memperbanyakkan aktiviti yang bersesuaian dengan jiwa belia seperti aktiviti sukan dan rekreasi. Aspek pendidikan pula perlu diperbanyakkan pusat kemahiran serta pemberian biasiswa kepada pelajar yang layak dan memerlukan, seterusnya bagi aspek politik mereka berharap agar perlunya pemimpin yang jujur, bersih, amanah dan mementingkan rakyat/pengundi di samping perlu diberi lebih ruang kepada mereka untuk berpolitik seterusnya menyuarakan pandangan mereka tentang politik semasa. Selain itu, dari sudut alam sekitar pula, mereka menyarankan pihak berkuasa agar menggerakkan aktiviti gotong royong dalam kalangan masyarakat setempat di samping mencantikkan landskap persekitaran agar lebih segar dan ceria.

Selain itu, Mohd Fuad et al. (2012) dalam penulisannya mendapati bahawa kriteria pemilihan pemimpin dan calon muda di DUN dan Parlimen negeri Kedah menunjukkan mereka meletakkan keutamaan kepada pemimpin yang berjiwa rakyat, mesra rakyat dan selalu turun padang untuk menemui mereka. Ini diikuti pemimpin yang jujur dan amanah, bersih daripada rasuah, mempunyai karisma dan ketokohan dan mementingkan perpaduan kaum dan agama. Kriteria-kriteria seperti mempunyai pengetahuan agama yang mendalam, kelayakan akademik yang tinggi, sebangsa, calon tempatan dan muda kurang mendapat keutamaan dari responden. Mohd Fuad et al. (2012)(b) juga dalam kajiannya terhadap persepsi kecenderungan politik belia India di Universiti Awam pula mendapati bahawa golongan belia India di Universiti Awam mahukan isu-isu penting dalam masyarakat India seperti isu pendidikan di sekolah Tamil, pemberian biasiswa, isu kuota, isu agama dan isu sosioekonomi diselesaikan segera oleh pemerintah dan dari segi keperluan calon pilihan yang ideal majoriti dari mereka memilih calon yang mempunyai karisma atau ketokohan, kelayakan akademik yang tinggi dan calon muda serta parti politik yang memperjuangkan isu kemanusiaan seperti ketelusan, keadilan, hak asasi manusia, anti rasuah; memperjuangkan isu alam sekitar.

Di samping itu, dapatan kajian Sivamurugan (2014) menunjukkan bahawa belia mahukan sebuah parti yang berbilang kaum dan inklusif untuk semua rakyat Malaysia tanpa mengira bangsa dan agama. Majoriti pengundi muda pelajar lebih mengambil berat tentang isu-isu umum yang melibatkan parti-parti politik di kedua-dua peringkat kebangsaan dan tempatan dan bukannya isu perkauman. Hasil kajian ini juga mendapati responden kaum Melayu dan kaum India lebih menyokong dasar yang telah dilaksanakan oleh Perdana Menteri tetapi sebaliknya bagi responden kaum Cina.

Namun begitu, apabila fokus terhadap tokoh pemimpin tertentu, kajian oleh Noor Amira Syazwani et al. (2012) mendapati sebaliknya. Dalam penyelidikan mereka didapati bahawa terdapat perbezaan yang ketara di antara pandangan belia yang terlibat dalam persatuan terhadap personaliti dan dasar-dasar awam Najib Tun Razak. Walau bagaimanapun, tiada perbezaan persepsi yang ketara di antara pandangan belia dari aspek jantina, etnik dan umur terhadap personaliti, pentadbiran dan dasar-dasar awam Najib Tun Razak. Kedua, hasil kajian mereka juga mendapati majoriti belia memberikan pandangan positif Najib Tun Razak yang telah menyediakan banyak peluang pendidikan kepada belia, peluang pekerjaan, dan mengurus tadbir ekonomi negara dengan baik sekali. Walau bagaimana pun, majoriti belia memberikan pandangan negatif terhadap Najib Tun Razak mengenai tugasnya menangani rasuah, kroni, dan nepotisma dan juga mengawal harga barangan di negara ini. Oleh itu, hasil kajian penyelidikan ini mendapati bahawa belia di Malaysia pada hari ini mempunyai kesedaran terhadap personaliti, pentadbiran dan dasardasar awam terhadap tokoh yang dikemukakan iaitu Najib Tun Razak kerana responden yang terbabit memberikan pandangan yang berbeza.

Faktor penentu parti politik yang telah dikaji oleh Norhayati (2008) dalam penyelidikannya tentang tsunami politik Melayu pada PRU-12 merangkumi faktor dalaman 
dan faktor luaran parti. Faktor dalaman parti merujuk kepada calon-calon yang bertanding. Faktor calon termasuklah calon muda yang berkarisma serta berpersonaliti menarik dan baik yang menjadi tarikan pengundi untuk mengundi sesebuah parti. Faktor luaran pula merujuk kepada isu-isu semasa seperti kenaikan kadar tol, harga barangan, berlakunya peningkatan kadar jenayah serius seperti pembunuhan dan rompakan, aduan rasuah, tuntutan kenaikan gaji pekerja akibat kenaikan kos sara hidup, tuntutan pelajar-pelajar universiti, tunjuk perasaan yang mahukan pilihan raya lebih adil, tunjuk perasaan oleh penduduk setinggan dan beberapa kes penyalah gunaan kuasa.

Namun kajian Weiss (2012), menunjukkan kuasa media baru untuk menyebarkan mesej, menyokong pemimpin, dan undi online tidak boleh dipandang remeh. Bukan itu sahaja, jurang digital telah memisahkan kawasan bandar dari kawasan pedalaman "desa" dan memberi implikasi terhadap membentuk keputusan pilihan raya.

Dalam konteks negeri Sabah, Eko et al. (2016) menyatakan bahawa penyertaan politik golongan muda tampaknya menunjukkan perubahan yang ketara. Suara-suara protes dan tuntuntan yang dahulunya sukar untuk disampaikan secara terbuka sudah menjadi sebahagian daripada perkembangan politik Sabah pada akhir-akhir ini. Protes, demonstrasi, wacana perbahasan politik dan gerakan rakyat semacam sudah menjadi aktiviti politik yang biasa dan digerakan secara efektif oleh golongan belia. Golongan belia di Sabah yang semakin terbuka dan kritikal terhadap sebarang bentuk ketidakadilan daripada pihak kerajaan terhadap masyarakat, pada hakikatnya masih ragu dan gentar dalam membuat keputusan berdasarkan keinginan dan kemandirian yang mereka inginkan. Di Sarawak pula, Junaidi et al. (2012) dalam kajiannya tentang PRU di DUN Sarawak yang bertujuan untuk mengenalpasti kriteria calon dan parti yang dimahukan oleh pengundi Sarawak. Kajian beliau mendapati majoriti daripada responden memilih calon yang berjiwa dan mesra rakyat, diikuti personaliti kepimpinan yang baik, jujur dan amanah serta tidak mengamalkan rasuah. Bagi parti politik pula, mereka akan memilih parti yang memperjuangkan ketelusan, keadilan, hak asasi dan anti-rasuah serta yang mampu membawa pembangunan dan membasmi kemiskinan. Keputusan Pilihan Raya Umum Dewan Undangan Negeri Sarawak (PRU DUN) Sarawak 2011 menunjukkan pola pengundian kaum Melayu/Melanau terus bertahan dengan sedikit peningkatan kepada Barisan Nasional (BN), namun bagi kaum Cina memperlihatkan sokongan mereka semakin meningkat kepada parti-parti pembangkang iaitu DAP dan PKR. Manakala bagi kaum Dayak (Iban, Bidayuh dan Orang Ulu) pula menunjukkan berlaku sedikit kemerosotan terhadap sokongan kepada BN. Walau bagaimanapun, Case (2013) dalam kajiannya menyatakan bahawa kemenangan BN pada PRU 13 adalah kerana cengkamannya ke atas pendukung Melayu di kawasan luar bandar, Sabah dan Sarawak. Selain itu, wujud juga prasangka etnik semasa kempen dijalankan. Agak berbeza pada PRU 14 apabila Dettman \& Gomez (2020), menyatakan perubahan yang berlaku dalam PRU 14 bukan hanya melibatkan sokongan parti pembangkang tetapi juga masyarakat madani yang merangkumi pelbagai peringkat pengundi termasuk pengundi muda.

Secara rumusannya, berdasarkan kajian penyelidik-penyelidik yang terdahulu didapati beberapa perkara penting tentang orang muda iaitu: (i) mereka cakna tentang politik Malaysia, (ii) Mempunyai kriteria pemilihan calon yang benar sangat rinci dan (iii) mereka benar-benar yakin bahawa calon yang mereka pilih mampu menyuarakan hasrat dan aspirasi mereka. Penulisan ini walaupun dilihat mempunyai sedikit persamaan seperti mana yang pernah dikemukakan oleh penyelidik-penyelidik yang terdahulu tadi tetapi ia mempunyai dua perbezaan yang sangat ketara iaitu (i) ia dijalankan sebelum PRU 14 yang mana dilihat pada PRU ini pengundi muda benar-benar meggunakan hak mereka (sebagai pengundi) dan (ii) ia merangkumi sampel yang besar iaitu 47,116 sampel yang mewakili 98 daripada keseluruhan 222 buah Parlimen di Malaysia. 


\section{Metodologi}

Kajian ini telah menggunakan kaedah gabungan iaitu kaedah kuantitatif dan kualitatif. Pengabungan kaedah ini membolehkan dapatan secara lebih terperinci, tepat dan mendalam (Bryman, 2006). Kaedah kuantitatif kajian ini adalah melalui edaran borang soal selidik yang meliputi domain pihak yang disokong, kriteria pemilihan, ciri-ciri calon, dasar parti dan isu semasa. Pemilihan kaedah soal selidik membolehkan maklumat terus daripada responden dilakukan secara bersemuka. Data numerikal yang diperoleh membantu mencapai tujuan kajian iaitu meneliti pola pengundian dalam kalangan orang muda di Malaysia pada Pilihan Raya Umum ke 14. Manakala kaedah kualitatif yang digunakan melibatkan analisis dokumen rasmi dan tidak rasmi seperti artikel jurnal serta keratan akhbar.

Data soal selidik dianalisis secara deskriptif yang melibatkan analisis frekuensi, peratusan, min dan sisihan piawai untuk meneliti profil responden dan tahap. Manakala analisis cross tab digunakan untuk melihat hubungan antara beberapa pemboleh ubah kajian. Dari segi sampel, kajian ini melibatkan seramai 47,116 responden daripada 98 Parlimen seluruh Malaysia. Sampel kajian ini merupakan golongan muda yang berumur 21 hingga 40 tahun yang dipilih secara rawak mudah. Namun sebelum memilih sampel secara rawak mudah kaedah persampelan sistematik digunakan untuk penetapan kawasan iaitu kawasan parlimen yang dikategorikan kepada empat pecahan lokasi iaitu urban, sub urban, luar bandar dan felda. Seterusnya setiap parlimen dipecahkan mengikut kawasan Dewan Undangan Negeri. Pemecahan kawasan ini membolehkan kutipan responden adalah secara menyeluruh. Kawasan kutipan sampel kajian adalah di rajah 1.

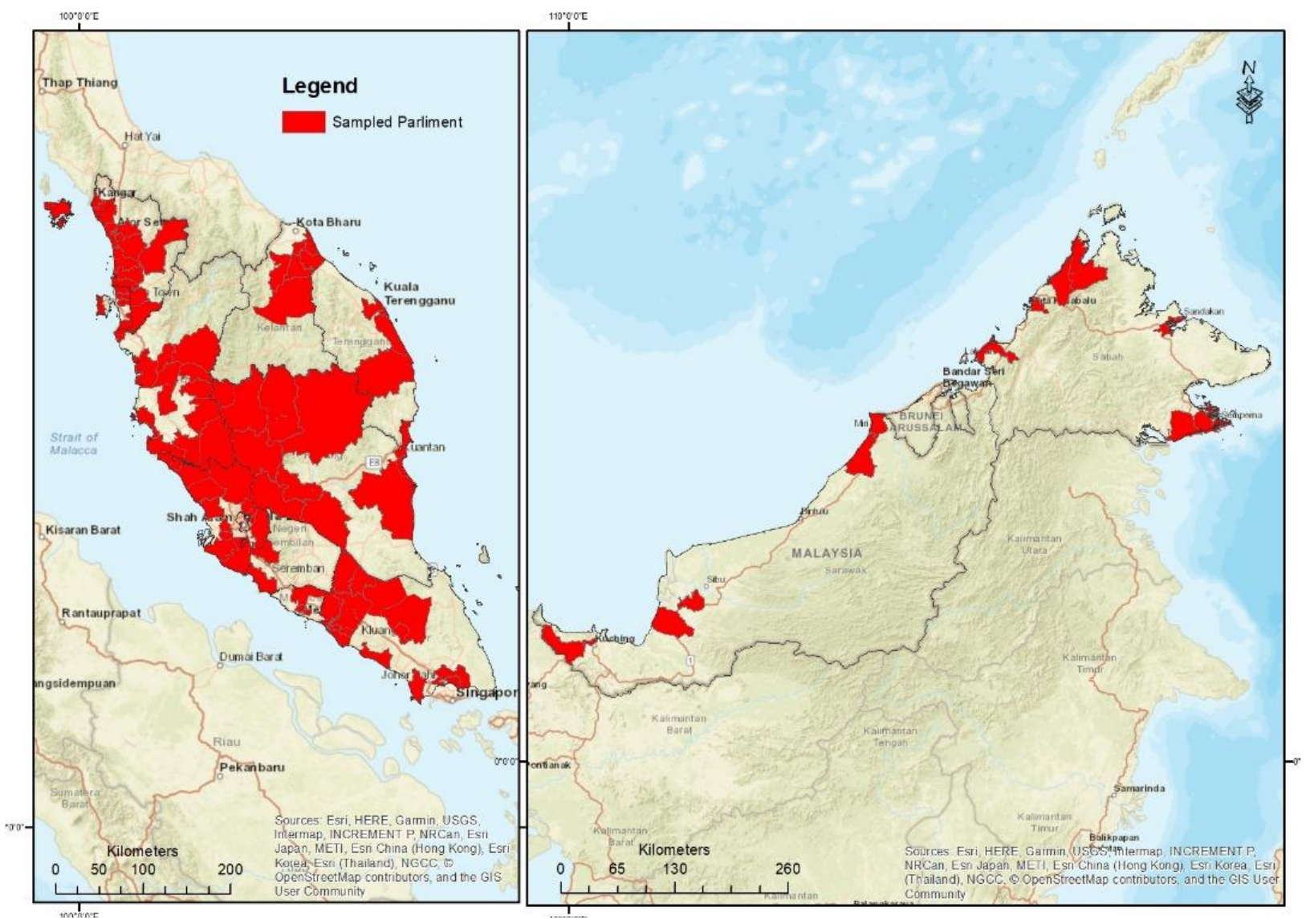

Rajah 1. Peta lokasi 98 kawasan Parlimen yang di sampel 


\section{Penemuan dan perbincangan}

\section{Latar belakang responden}

Secara keseluruhannya, daripada keseluruhan 98,000 responden dari 98 buah Parlimen yang di sampel, 47,116 orang daripadanya merupakan pengundi muda (berumur 21-40 tahun). Profil jantina pengundi muda menunjukkan pengundi lelaki adalah seramai 25,788 (54.7\%) orang dan pengundi wanita adalah seramai 21,328 orang $(45.3 \%)$. Seterusnya analisis profil responden mengikut kelompok bangsa mendapati pengundi Melayu adalah seramai 30,800 orang (65.4\%), Cina seramai 7,706 orang (16.4\%), India seramai 3,625 orang $(7.7 \%)$ dan lain-lain bangsa seramai 4,985 orang (10.6\%) (Jadual 1).

Jadual 1. Latar belakang responden

\begin{tabular}{llcc}
\hline Latar belakang responden & Bilangan & Peratus \\
\hline \multirow{2}{*}{ Jantina } & Lelaki & 25,788 & 54.7 \\
& Perempuan & 21,328 & 45.3 \\
\multirow{4}{*}{ Kaum } & Jumlah & 47,116 & 100.0 \\
& Melayu & 30,800 & 65.4 \\
& Cina & 7,706 & 16.4 \\
& India & 3,625 & 7.7 \\
& Lain & 4,985 & 10.6 \\
& Jumlah & 47,116 & 100.0 \\
\hline
\end{tabular}

Manakala dari segi taburan lokasi pula, sejumlah 9,365 responden (19.9\%) merupakan pengundi di kawasan bandar, 9,532 responden $(20.2 \%)$ merupakan pengundi di kawasan pinggir bandar, 15,765 responden (33.5\%) adalah pengundi luar bandar, manakala selebihnya 12,454 responden (26.4\%) merupakan pengundi di kawasan Felda (Jadual 2).

Jadual 2. Taburan lokasi responden mengikut kawasan

\begin{tabular}{lcc}
\hline Lokasi kawasan & Bilangan & Peratus \\
\hline Bandar & 9365 & 19.9 \\
Pinggir bandar & 9532 & 20.2 \\
Luar bandar & 15765 & 33.5 \\
Felda & 12454 & 26.4 \\
Jumlah & 47116 & 100.0 \\
\hline
\end{tabular}

Akhir sekali, daripada sejumlah 47,116 responden ini seramai 40,874 orang $(86.8 \%)$ telah mengundi pada PRU ke 13 (2013), manakala selebihnya iaitu 6,242 responden (13.2\%) merupakan pengundi kali pertama.

\section{Faktor mempengaruhi golongan muda menyokong parti yang bertanding}

Kajian ini telah menetapkan sembilan item tertutup pilihan responden untuk menyokong parti (Jadual 3). Berdasarkan keseluruhan pilihan tersebut, responden pengundi muda memilih "kerap turun padang/mesra rakyat" sebagai kriteria utama dengan peratusan tertinggi iaitu seramai 23,544 orang (50.0\%). Pilihan ke dua golongan ini adalah manifesto yang lebih baik untuk masa depan negara iaitu seramai 22,878 orang (48.6\%). Pilihan ketiga adalah "parti yang telah berjaya" iaitu seramai 20,945 orang $(44.5 \%)$. 
Jadual 3. Faktor mempengaruhi golongan muda menyokong parti yang bertanding

\begin{tabular}{|c|c|c|c|c|c|c|}
\hline \multirow[t]{2}{*}{ Item Pilihan } & \multicolumn{2}{|c|}{ Ya } & \multicolumn{2}{|c|}{ Tidak } & \multirow{2}{*}{$\begin{array}{c}\text { Pearson } \\
\text { Chi-Square }\end{array}$} & \multirow{2}{*}{$\begin{array}{l}\text { Asymp. Sig. } \\
\text { (2-sided) }\end{array}$} \\
\hline & Bil & $\%$ & Bil & $\%$ & & \\
\hline Parti yang telah berjasa & 20945 & 44.5 & 26171 & 55.5 & $122.215 \mathrm{a}$ & .000 \\
\hline $\begin{array}{l}\text { Manifesto yang lebih baik } \\
\text { untuk masa depan negara }\end{array}$ & 22878 & 48.6 & 24238 & 51.4 & $.213 \mathrm{a}$ & .644 \\
\hline Berintegriti & 17452 & 37.0 & 29664 & 63.0 & $39.569 a$ & .000 \\
\hline Progresif/pejuang kemajuan & 10116 & 21.5 & 37000 & 78.5 & $38.356 a$ & .000 \\
\hline $\begin{array}{l}\text { Pemimpin yang berpandangan } \\
\text { jauh dan terbuka }\end{array}$ & 18485 & 39.2 & 28631 & 60.8 & $.056^{\mathrm{a}}$ & .812 \\
\hline $\begin{array}{l}\text { Kerap turun padang/mesra } \\
\text { rakyat }\end{array}$ & 23544 & 50.0 & 23572 & 50.0 & $6.206^{\mathrm{a}}$ & .013 \\
\hline $\begin{array}{l}\text { Dapat menunaikan janji } \\
\text { mengikut manifesto }\end{array}$ & 17942 & 38.1 & 29174 & 61.9 & $1.096 \mathrm{a}$ & .295 \\
\hline Tidak perkauman & 10800 & 22.9 & 36316 & 77.1 & $21.828 \mathrm{a}$ & .000 \\
\hline $\begin{array}{l}\text { Sesuai dengan masyarakat } \\
\text { majmuk }\end{array}$ & 12040 & 25.6 & 35076 & 74.4 & $2.669 \mathrm{a}$ & .102 \\
\hline
\end{tabular}

Dari segi faktor pemilihan anak muda terhadap parti dalam pilihan raya, Mohd Haziman (2017) menegaskan bahawa anak muda cenderung untuk memilih calon yang mempunyai sikap integriti, moral, hak asasi, dan bersikap demokratik kerajaan dalam mengurus aspirasi rakyat selain dari parti yang menawarkan dasar yang mengutamakan kepentingan di masa hadapan (manifesto). Penemuan kajian Mohd Fuad dan Junaidi (2012) di Parlimen Muar mendapati bahawa anak muda mahukan pemimpin yang bersifat jujur, bersih, amanah dan mementingkan rakyat/pengundi dan mahukan ruang yang lebih untuk menyuarakan pendapat mereka tentang politik semasa. Selain itu, golongan muda turut memilih parti yang pemimpinnya bersifat jujur, amanah, mesra dan bebas dari rasuah (Mohd Fuad et al., 2012).

Analisis empirikal juga menunjukkan empat pilihan yang menunjukkan hubungan yang tidak signifikan dalam kelompok pengundi muda bagi yang menjawab "ya" (setuju) dan "tidak" iaitu "Manifesto yang lebih baik untuk masa depan negara" [x2=.213 p>.05], "Pemimpin yang berpandangan jauh dan terbuka" $[\mathrm{x} 2=.056 \mathrm{p}>.05]$, "Dapat menunaikan janji mengikut manifesto" [x2=1.096 p>.05] dan "Sesuai dengan masyarakat majmuk" [x2=2.669 p>.05]. Ini bermakna dapatan kajian menunjukkan ke keempat-empat item pilihan responden yang tidak signifikan ini memperlihatkan terdapat pilihan kesamaan jawapan bagi kelompok "Ya" dan "Tidak" dalam faktor yang mempengaruhi mereka memilih pemimpin.

\section{Media yang paling dipercayai oleh pengundi muda}

Maklumat adalah salah satu elemen yang paling penting dalam sesebuah pilihanraya. Walaupun sesebuah parti politik itu mempunyai wadah perjuangan yang terbaik tetapi jika ia tidak disampaikan melalui sumber yang betul akhirnya akan menyebabkan matlamat dan hasrat perjuangan sesbuah parti itu tidak sampai ke peringkat pelbagai lapisan pengundi. Menurut Samsudin (2010), media termasuk internet memberikan ruang baru dalam demokrasi bukan sahaja untuk mencapai maklumat tetapi memberikan ruang interaksi dalam komunikasi politik. Bagi proses demokrasi berjaya, ia memerlukan maklumat untuk membolehkan warga sesebuah negara membuat keputusan dengan bijak. Maka itu, akses kepada maklumat yang sahih dan berkualiti daripada pelbagai media bagi setiap warganegara adalah penting (Shamsudin, 2010).

Analisis seterusnya berhubung jenis maklumat yang paling dipercayai oleh pengundi muda ini mendapati pengundi muda memilih untuk mempercayai sumber elektronik iaitu seramai 16,217 orang (34.4\%). Ini diikuti oleh sumber media cetak seramai 13,516 orang 
(28.7\%) dan pilihan ke tiga tertinggi adalah media online/sosial seramai 10,531 orang (22.4\%). Penemuan ini menyokong pandangan Mohd Hariszuan (2014) bahawa terdapat satu proses pembentukan identiti melalui budaya popular dalam kalangan masyarakat Malaysia khas dalam kalangan orang muda yang membezakan mereka dengan generasi sebelumnya di mana mereka lebih cenderung untuk mempercayai media elektronik yang dilihat lebih bebas berbanding media cetak yang dianggap masih dikongkong pemerintah.

Jadual 4. Jenis sumber maklumat yang dipercayai

\begin{tabular}{lcc}
\hline Media & Bilangan & Peratus (\%) \\
\hline Media elektronik & 16,217 & 34.4 \\
Media cetak & 13,516 & 28.7 \\
Media online/sosial & 10,531 & 22.4 \\
Lain-lain & 6,104 & 13.0 \\
Tidak pasti & 547 & 1.2 \\
Tidak menjawab & 201 & 0.4 \\
Jumlah & 47,116 & 100.0 \\
\hline
\end{tabular}

Menurut Noor Mohammad (2018), Institut Teknologi Massachusetts (MIT), Amerika Syarikat telah merumuskan bahawa berita palsu lebih cepat tersebar di internet berbanding berita yang sahih. Daripada 126,000 berita palsu dalam Twitter pada 2016 dan 2017, semua berita palsu itu di kicau (tweet) oleh tiga juta hingga 4.5 juta kali sepanjang tempoh berkenaan. Malah kira-kira 70 peratus maklumat palsu disebarkan lebih banyak berbanding berita benar terutama pada peristiwa besar seperti kempen pemilihan Presiden AS. Menurut beliau lagi, lebih mengejutkan apabila didedahkan berita benar mengambil masa enam kali lebih lama untuk disampaikan dan penyelidik merumuskan berita palsu cepat tersebar kerana ia mengujakan berbanding maklumat sebenar. Ini jelas membuktikan bahawa berita palsu terutamanya di media elektronik adalah masalah global dan setiap individu mesti berhati-hati dalam menerima dan menghadam segala berita/maklumat tersebut.

Lanjutan dari itu, responden juga turut disoal sama ada mereka menilai semula maklumat yang diterima (Jadual 5). Hasil kajian mendapati seramai 27,061 responden (57.4\%) menilai semula maklumat yang mereka peroleh dari pelbagai sumber media. Manakala seramai 9,888 responden $(21.0 \%)$ memilih untuk tidak berbuat sedemikian. Selain itu, ada juga yang memilih "Tiada masa" iaitu seramai 7,736 responden (16.4\%) dan menganggap bahawa ia tiada perlu iaitu seramai 2,100 responden $(4.5 \%)$.

Berdasarkan penemuan ini jelas didapati bahawa majoriti responden (pengundi muda) di Malaysia bukanlah dari jenis yang hanya menerima maklumat secara semberono sematamata sebaliknya mereka akan membuat semakan sebelum menerima dan mempercayai sesuatu maklumat/berita. Ini adalah satu petanda baik ke arah masyarakat yang celik maklumat dalam melahirkan demokrasi yang lebih matang.

Jadual 5. Menilai sumber maklumat yang diterima

\begin{tabular}{lcc}
\hline Menilai Maklumat & Bilangan & Peratus \\
\hline Ya & 27,061 & 57.4 \\
Tidak & 9,888 & 21.0 \\
Tiada masa & 7,736 & 16.4 \\
Tidak perlu & 2,100 & 4.5 \\
Tidak pasti & 93 & 0.2 \\
Tidak menjawab & 238 & 0.5 \\
Jumlah & 47,116 & 100.0 \\
\hline
\end{tabular}




\section{Pandangan terhadap parti-parti politik baharu}

Pasca PRU 13 menyaksikan perkembangan yang lebih menarik dalam politk Malaysia. Pergolakan dalam PAS telah mendorong kepada kewujudan Parti Amanah Negara yang dilancarkan pada 16 September 2015. Selain itu, pemecatan Tan Sri Muhyiddin Yassin dan Dato' Seri Paduka Mukhriz Mahathir daripada UMNO pada 24 Jun 2016 telah membawa kepada penubuhan Parti Pribumi Bersatu Malaysia (PPBM) pada 8 September 2016. Manakala penggantungan Dato' Seri Mohd Shafie Apdal daripada UMNO telah membawa kepada penubuhan Parti Warisan Sabah pada 17 Oktober 2016.

Jadual 6 adalah analisis terhadap pandangan penubuhan dan peranan parti baharu dalam kancah politik semasa terhadap kelompok pengundi muda mendedahkan bahawa 33,725 orang $(71.6 \%)$ mengetahui berkenaan parti politik baharu berbanding hanya 13,391 orang $(28.4 \%)$ sahaja tidak mengetahui. Ini menunjukan bahawa golongan muda memerhati dan mengetahui perkembagan parti-parti politik di Malaysia. Namun demikian, berdasarkan hasil soal selidik yang dijalankan didapati walaupun mereka mengetahui adanya parti-parti politik baharu, majoriti responden $(65.1 \%)$ jelas tidak menyokong penubuhan parti politik ini.

Jadual 6. Pandangan terhadap parti-parti politik baharu

\begin{tabular}{lcccc}
\hline Item Pilihan & \multicolumn{2}{c}{ Ya } & \multicolumn{2}{c}{ Tidak } \\
\cline { 2 - 5 } & Bil & \% & Bil & \% \\
\hline Mengetahui penubuhan parti politik baru (PAN, & 33,725 & 71.6 & 13,391 & 28.4 \\
PPBM, PH \& Warisan) & & & & \\
Menyokong penubuhan parti politik baharu & 16,461 & 34.9 & 30,655 & 65.1 \\
Parti baharu boleh menang pada peringkat nasional & 15,203 & 32.3 & 31,913 & \\
dalam PRU-14 & & & & 67.7 \\
Parti baharu tidak boleh bertahan lama & 20,936 & 44.4 & 26,180 & 55.6 \\
Parti baharu mampu menggantikan kerajaan & 15,072 & 32.0 & 32,044 & 68.0 \\
$\begin{array}{l}\text { Parti baharu telah memecahkan perpaduan orang } \\
\text { melayu }\end{array}$ & 20,589 & 43.7 & 26,527 & 56.3 \\
& & & & \\
\end{tabular}

Selain dari itu, sejumlah 31,913 responden (67.7\%) tidak meyakini bahawa parti-parti politik baharu ini boleh memenangi PRU 14. Majoriti juga berpandangan bahawa parti-parti baharu ini tidak akan bertahan lama (44.4\%) dan mampu menggantikan kerajaan sedia ada (32\%). Namun begitu, responden kurang bersetuju bahawa parti-parti politik baharu membawa kepada perpecahan orang Melayu di mana daripada keseluruhan responden hanya 43.7\% sahaja yang percaya bahawa perpecahan orang Melayu akan berlaku dengan penubuhan parti-parti politik baharu ini.

\section{Pihak yang disokong pada PRU 13}

Kajian turut menganalisis pihak yang disokong oleh responden di peringkat Parlimen dan Dewan Undangan Negeri pada PRU 13 yang lalu (Jadual 7). Di peringkat Parlimen, hasil dari soal selidik yang dijalankan didapati majoriti pengundi muda telah memilih Barisan Nasional sebagai parti pilihan mereka di peringkat Parlimen. Penemuan mendapati seramai 26,850 orang (57.0\%) memilih Barisan Nasional, diikuti dengan 14,024 (29.8\%) yang memilih Pakatan Rakyat seramai dalam PRU 13 yang lalu. Diperingkat Dewan Undangan Negeri (DUN) senario yang sama juga berlaku. Hasil analisis mendapati majoriti responden iaitu seramai 25,233 orang (55.5\%) memilih Barisan Nasional sebagai wakil mereka di peringkat DUN manakala 14,058 orang (30.9\%) memilih Pakatan Rakyat.

Selain itu, di peringkat Parlimen terdapat juga responden yang memilih jawapan "Tidak pasti" iaitu seramai 3,071 orang $(6.6 \%)$ dan seramai 3,171 orang $(6.7 \%)$ "Tidak menjawab". 
Manakala di peringkat DUN, seramai 2,879 orang (6.3\%) menjawap "Tidak pasti" dan yang tidak menjawab adalah seramai 3266 orang (7.9\%). Pemilihan ini didorong oleh dua kemungkinan iaitu (i) Responden tidak mengundi pada PRU 13 dan (ii) responden khuatir untuk mendedahkan parti pilihan mereka kerana menganggapnya sulit dan tidak perlu didedahkan kepada orang lain.

Jadual 7. Parti pilihan semasa Parlimen (PRU 13)

\begin{tabular}{lcccccccc}
\hline \multirow{2}{*}{ Peringkat } & \multicolumn{2}{c}{ BN } & \multicolumn{2}{c}{ PR } & \multicolumn{2}{c}{ Tidak Pasti } & \multicolumn{2}{c}{ Tidak Menjawab } \\
\cline { 2 - 9 } & Bil. & \% & Bil. & \% & Bil. & \% & Bil. & \% \\
\hline Parlimen & 26850 & 57.0 & 14024 & 29.8 & 3071 & 6.5 & 3171 & 6.7 \\
Dewan Undangan Negeri & 25233 & 55.5 & 14058 & 30.9 & 2879 & 6.3 & 3266 & 7.9 \\
\hline
\end{tabular}

\section{Parti yang dimahukan untuk memerintah negara selepas PRU 14}

Akhir sekali, responden turut ditanya tentang parti yang bakal mereka pilih untuk menerajui negara selepas PRU ke 14 (Jadual 8). Daripada tiga kumpulan utama parti yang bertanding dalam PRU 14, Pakatan Harapan menjadi pilihan utama mendapat responden pengundi muda iaitu seramai 22,338 orang (47.4\%), diikuti Barisan Nasional seramai 10,243 orang $(21.7 \%)$ dan Gagasan Sejahtera seramai 4,755 orang (10.1\%). Selain itu terdapat juga kelompok responden yang dikategorikan sebagai 'pengundi atas pagar' kerana tidak tidak pasti akan mengundi atau memilih parti mana dalam PRU 14 (seramai 8,825 orang atau 18.7\%) dan selebihnya iaitu seramai 955 orang (2.0\%) tidak menjawab soalan yang dikemukakan.

Jadual 8. Parti pilihan memerintah negara selepas PRU 14

\begin{tabular}{lcc}
\hline Parti Pilihan & Bilangan & Peratus (\%) \\
\hline Pakatan Harapan & 22,338 & 47.4 \\
Barisan Nasional & 10,243 & 21.7 \\
Gagasan Sejahtera & 4,755 & 10.1 \\
Tidak Pasti & 8,825 & 18.7 \\
Tidak Menjawab & 955 & 2.0 \\
Jumlah & 47,116 & 100.0 \\
\hline
\end{tabular}

Penemuan ini sebenarnya agak mengejutkan kerana daripada keseluruhan responden yang terdiri dari mereka yang berumur 21-40 tahun iaitu 28,219 orang (59.9\%) daripadanya adalah terdiri dari mereka yang tinggal di kawasan luar bandar dan FELDA. Penemuan ini dirujuk oleh Mohd Hariszuan (2014) sebagai orientasi politik antara orang muda di bandar dan di luar bandar yang pada masa kini sudah tidak banyak perbezaannya. Perkara ini sangat penting kerana ia menunjukkan orientasi politik orang muda tidak lagi boleh dibahagikan mengikut sosio-ekonomi, sebaliknya nilai yang mereka pegang kini rentas kaum dan kelas ekonomi, walaupun ia bertentangan dengan Mohd Fuad dan Junaidi (2012) dalam penemuan mereka sebelum PRU ke 13 di Parlimen Muar, Johor. Namun demikian perbandingan ini tidaklah adil memandangkan bahawa dalam tempoh masa PRU ke 13 hingga ke PRU 14 suasana politik Malaysia sudah banyak berubah.

\section{Rumusan}

Harus diakui bahawa golongan muda sangat penting dalam menentukan keputusan sesuatu pilihan raya. Malah trend pertambahan golongan muda yang mendaftar sebagai pengundi adalah satu situasi yang baik dan perlu diambil peduli oleh setiap parti politik. Golongan 
muda adalah golongan yang sering dilihat sebagai 'rebel', 'anti establisment' serta menganut fahaman politik baru iaitu politik yang merentasi sempadan bangsa dan agama serta bersifat universal. Walaupun sering dihebahkan di media bahawa anak muda tidak menyokong kerajaan dan cenderung kepada pembangkang namun pembuktian tidak ditunjukkan dalam kajian-kajian saintifik kecuali kaji selidik yang dijalankan oleh Merdeka Centre antara 2012 dan 2013 mendapati golongan muda secara konsisten bersikap kritikal terhadap prestasi kerajaan pimpinan Najib Razak. Umumnya mereka yang berumur antara 20 hingga 40 tahun mahukan perubahan dasar negara dan pendekatan politik yang lebih rasional antaranya mengadakan debat berkenaan dasar ekonomi antara Najib Razak dan Anwar Ibrahim.

Penemuan dalam kajian ini telah membuktikan tiga penemuan penting sebelum PRU 14 yang berkaitan dengan kecenderungan orang muda di Malaysia untuk memilih dalam pilihanraya iaitu (i) kecenderungan mereka untuk memilih calon/parti, (ii) kepercayaan mereka terhadap media dan akhir sekali (iii) suara mereka yang inginkan perubahan dalam pemerintah Malaysia pasca PRU 14. Walaupun persampelan yang terakhir dalam kajian ini adalah pada bulan April 2017 iaitu lebih setahun sebelum PRU ke 14, tetapi kecenderungan dan aspirasi anak muda telah kelihatan pada masa tersebut. Keadaan ini seterusnya di semarakkan lagi oleh tiga perkara dalam politik Malaysia ketika PRU ke 14 semakin hampir iaitu (i) PH mengumumkan Tun Dr Mahathir Mohamad sebagai calon Perdana Menteri ketujuh dan Dato Seri Anwar Ibrahim akan diangkat sebagai calon Perdana Menteri kelapan, (ii) Kempen Jelajah Pakatan ke setiap negeri dan (iii) cercaan berterusan dari pemimpin BN terhadap Tun Dr Mahathir Mohamad.

Justeru tidak hairanlah dalam PRU 14, kemenangan jatuh ke tangan PH yang berjaya memecahkan monopoli BN selama 60 tahun apabila memenangi 113 daripada 222 kerusi Parlimen (tambahan 8 kerusi di Sabah yang dimenangi oleh parti sekutu PH iaitu Warisan). Kemenangan ini juga menyaksikan $\mathrm{PH}$ memperoleh 48 peratus undi popular. BN, 34 peratus undi popular dan Gagasan Sejahtera pula mendapat 17 peratus undi popular daripada keseluruhan 12,299,514 yang keluar mengundi pada 9 Mei 2014.

PRU ke 14, menyaksikan perubahan kerajaan telah berlaku di Malaysia secara aman. Kerajaan baru dipilih oleh rakyat melalui saluran demokrasi iaitu pilihanraya. Ini merupakan sejarah baharu buat Malaysia dan sebahagian dari yang turut serta mencipta sejarah tersebut ialah pengundi muda.

\section{Rujukan}

Abdul Hadi, Samsi. (2014). Penglibatan belia dalam politik di Selangor. (Tesis Sarjana). Universiti Putra Malaysia. Tidak Diterbitkan.

Berita Harian. (6 Mac 2018). Pengundi muda mampu buat kejutan PRU-14. Di Akses pada 28 Ogos 2018.

Case, W. (2013) Post-GE13: Any Closer to Ethnic Harmony and Democratic Change?, The Round Table, 102:6, 511-519, DOI: 10.1080/00358533.2013.857147

Dettman, S., \& Gomez, E.T. (2020) Political financing reform: Politics, policies and patronage in Malaysia. Journal of Contemporary Asia, 50(1), 36-55, DOI: 10.1080/00472336.2019.1571218

Eko Prayitno Joko, Zaini Othman, \& Saat Awg. Damit. (2016). Belia dan kelangsungan hegemoni Barisan Nasional: Kajian Kes Pilihan Raya Umum 13 di Sabah. Jurnal Komunikasi, 14, 1-18.

Junaidi Awang Besar, \& Mohd Fuad Mat Jali. (2011). Keperluan Belia dan pendapat politik di kawasan parlimen Muar, Johor. Persidangan Kebangsaan Geografi \& Alam Sekitar 
Kali Ke-3, Universiti Pendidikan Sultan Idris (UPSI), Tanjung Malim, Perak. 8-10 Februari 2011.

Junaidi Awang Besar, Mohd Fuad Mat Jali, Yahaya Ibrahim, Novel Lyndon, Khaidzir Hj. Ismail, Noor Aziah Hj. Mohd Awal, Jeniri Amir, Ahi Sarok, Rosmadi Fauzi, \& Amer Saifude Ghazali. (2012). Kriteria pemilihan calon dan parti dalam Pilihan Raya Umum Dewan Undangan Negeri Sarawak. Geografia: Malaysia Journal of Society and Space, 8(4), 44-55.

Mohd Fuad Mat Jali, Junaidi, A.B., Amriah Buang, Mohd Jalaluddin Hashim, Novel Lyndon, Hamzah Jusoh, H.A., Sivapalan Selvadurai, Er Ah Choy, \& Mohd Yusof Hussain. (2012). Pengaruh politik alam sekitar terhadap persepsi pengundi: Kajian kes DUN Kedah. Geografia: Malaysia Journal of Society and Space, 8(6), 117-133.

Mohd Fuad Mat Jali, Junaidi Awang Besar, Novel Lyndon, \& Viknesh Ramachandran. (2012). Persepsi politik belia India di Institusi Pengajian Tinggi Awam (IPTA) Malaysia. Geografia: Malaysia Journal of Society and Space, 8(8), 1-11.

Mohd Fuad Mat Jali, \& Junaidi Awang Besar. (2012). Pendapat dan keperluan generasi muda di kawasan Parlimen Muar, Johor. E-Bangi-Journal of Social Sciences and Humanities, 7(1), 50-63.

Mohd Fuad Md Jali, Junaidi Awang Besar, Rosmadi Fauzi, Amer Saifudee Ghazali, Novel Lyndon, \& Mazlan Ali. (2012). Politik bandar: Persepsi dan tingkal laku politik pengundi di kawasan Petaling Jaya Selatan dan Batu. Akademika, 81(2), 61-75.

Mohd Hariszuan Jaharudin. (2014). Pilihanraya Umum Ke 13: Perubahan budaya politik Malaysia dan krisis legitimasi moral Barisan Nasional. Kajian Malaysia, 32(2), 149-169.

Mohd Haziman Mahmood. (2017). Impak Penyertaan Pengundi Muda Dalam PRU 2013 Terhadap Politik Malaysia. E-Bangi-Journal of Social Sciences and Humanities, 2(2), 115.

Mohd Nizar Sudin, Mohd Fuad Mat Jali, Junaidi Awang Besar, \& Marlisa Abdul Rahim. (2017). Kerelevenan calon muda menjelang pilihanraya umum ke 14. The 2nd International Conference on Communication, Media, Information Technology, Environment, Tourism, Economics, Politics, Arts and Heritage (ICDETAH 2017) 19-21 Mac 2017, Kuala Terengganu, Malaysia.

Mujibu Abd. Muis, Zaliha Hj Hussin, \& Badrul Azmier Mohamed. (2011). Perubahan generasi dan perkembangan demokrasi di Malaysia pasca pilihan raya umum ke-12. Dlm. Mohd. A. Sani, \& Aziz, A.R.A. (pnyt.), Agenda Ketahanan Nasional Malaysia, Sintok: IPDM, Universiti Utara Malaysia.

Müller, D. (2013). Post-islamism or pop-islamism? Ethnographic observations of Muslim youth politics in Malaysia. Paideuma: Mitteilungen Zur Kulturkunde, 59, 261-284. Retrieved February 10, 2020, from www.jstor.org/stable/24672388.

Noor Amira Syazwani, A.R., Mohd Rozaimy, R., \& Sharifah Syahirah, S.S. (2012). Persepsi golongan belia mengenai personaliti, pentadbiran dan dasar Najib Tun Razak. The 8th International Malaysian Studies Conference di Universiti Kebangsaan Malaysia Julai 2018.

Noor Mohamad Shakil Hamee. (2018). Tangani berita palsu dalam Berita Harian 29 Mac 2018.

Norhayati Mohd Saleh. (2008). Pilihan Raya Umum ke-12 (PRU-12): "Tsunami” politik Melayu? Jebat, 35, 49-64.

Rosmadi Fauzi. (2006). Geografi politik, pilihanraya dan aplikasi Sistem Maklumat Geografi (GIS) di Malaysia. JATI-Journal of Southeast Asian Studies, 11, 157-177.

Samsudin A. Rahim. (2010). Media, demokrasi dan generasi muda: Analisis keputusan Pilihanraya Umum Ke 12. Jurnal Komunikasi,-Malaysian Journal of Communication, 26(2), 1-15. 
Siti Noranizahhafizah Boyman. (2017). Students and Campus Elections: Case study at Sultan Idris Education University, Malaysia. International Journal of Humanities and Social Sciences, 9(6), 32-45.

Sivamurugan Pandian. (2014). University students and voting behavior in general elections: Perceptions on Malaysian political parties leadership. Asian Social Science, 10(18), 225231.

Welsh, B., \& Hsien Chang, A.C. (2012). Political change, youth and democratic citizenship in Cambodia and Malaysia. Paper presented at the Conference on Democracy and Citizen Politics in East Asia, Taipei.

Weiss, M.L. (2011). Student activism in Malaysia: crucible, mirror, sideshow. National University of Singapore: Singapura.

Weiss, M.L. (2012). Politics in cyberspace: New media in Malaysia. Berlin, fesmedia Asia, Friedrich-Ebert-Stiftung. 